\title{
Moving Beyond the Glass Ceiling?
}

\author{
Joan Tronto, Michael Bernhard, and Daniel O'Neill
}

\section{The Special Section}

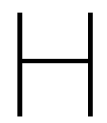

ow much progress have political scientists made in thinking about women's continuing unequal access to political power? The four articles and one reflection in this section come from different subspecializations in the discipline and use different methods and paradigms to approach this question. Each also seems to provide a different analysis of the problem and thus of its solution. We consider each in turn and then offer some provocations to the field.

In their essay, Danielle M. Thomsen and Bailey K. Sanders use a new dataset - an audit of state legislators - to revisit a longstanding issue in studies of gender in legislatures. The literature has argued that women do more "legislative" work than men, giving more speeches, sponsoring more bills, and the like but little is known about whether women are also better at constituent services. Thomsen and Sanders use an audit methodology to elicit responses from legislators to constituent inquiries. They establish that women legislators are also more attentive to constituents than men. This finding leads them to claim that "our results provide further motivation for increasing the number of women, especially conservative women, in politics." They conclude that "the evidence is mounting that the quality of legislative representation is simply better for both female and male citizens who are represented by women."

These findings are interesting, and Thomsen and Sanders have drawn a conclusion from them about representation-that women are better representatives. It is therefore perhaps ironic to argue that if women are better then they deserve equality. ${ }^{1}$ As they point out, in recounting that as legislators, women "outperform" men. "In short, as Fulton (2012) aptly notes, women need to 'run backwards and in high heels' to compete equally with men."

Is it is time for us to be perhaps more wary of the logic of the "glass ceiling" metaphor that Thomsen and Sanders seem to use? A closer reading of their article also suggests that it is operating within that paradigm. The glass ceiling is a popular metaphor to describe how women invisibly are kept out of male positions of power in society. But the metaphor brings other assumptions with it. It works by implying that the barriers to power experienced by women (or others in marginalized positions) would be "cracked" or "shattered" once the first woman president, astronaut, stock broker, and so forth breaks through the glass. This suggests that the exclusion is invisible yet transparent and relatively easy to break, and that once breached the problem of unequal access to power will then be gone. One of the reassuring qualities of this metaphor is that if women change their behavior-i.e., do better-they can break through. But perhaps we should notice that this view entails a shift in responsibility to make the change happen. Sheryl Sandberg's "lean in" approach (Sandberg and Scovell 2013), discussed in the article by Alter, et. al. is another version of this paradigm. As Alter, et. al. comment about the "lean in" approach, it shifts the onus back to women to fix the problem of their lack of power.

Another way to think about the problem of women's unequal access to power is to ask whether our analyses require, to borrow a title from sociologist Barbara Reskin, "Bringing the Men Back In" (1988). Rather than simply focusing on what women do, it may be time to look as well at what men do, and at ways in which structures of power, not a simple sheet of glass (no matter how thick), impedes the achievement of more equal power sharing. Here, for example, a question for future research might be if men are not doing more legislating or more constituent service work, what are they doing with their time as legislators? Are they building informal networks that lead to less tangible but perhaps greater forms of informal power?

Shifting from legislatures to another domain of power, our next article considers the power implied in labeling scholars noteworthy in political science itself. In "Gender and Status in American Political Science: Who Determines Whether a Scholar Is Noteworthy?” Karen J. Alter, Jean Clipperton, Emily Schraudenbach, and Laura Rozier also make a comparison between men and women, turning the spotlight on power inequalities to the differences in how men and women in leading political science departments are deemed "notable." Using a variety of databases that they created, the authors show that while elite institutions "reflect gender balances in our profession," when it comes to distinguishing between being notable through honorific or service-laden roles, "women are disproportionately congregated in categories with low status/high 
service." 2 Using their analysis to assess the "lean-in" hypothesis directly, they discover that "on average lower level leaning-in does not necessarily translate to recognition in the form of appointments to the Highest Honor and Leadership categories." They make a number of suggestions to rectify this situation. First, they argue that since there is no gender parity in being honorifically notable, correcting the imbalance will require a shift in responsibilities: "men should be fulfilling 70\% of Committee and mid-level management roles." They also argue that there needs to be greater "social accountability" for these imbalances. But what does social accountability mean here? Why do women end up disproportionately in such heavy service, low status roles? Do men receive better advice or are they - given the shape of private sphere in most of the United States - more practiced in avoiding service? Does power flow more freely in such channels as informal networks of friendships among men? These questions cannot be answered from these fascinating data sets, but they do suggest agendas for further research.

Regina Bateson's article, "Strategic Discrimination," reports on some experimental work in support of this new conceptual framing. Focusing on both gender and race, Bateson describes strategic discrimination as a subset of the question of "electability" or as a form of "pluralistic ignorance." Using a series of experiments, she shows that since Americans "typically overestimate others' levels of intolerance," they presume that others will not vote for a candidate who seems different, and thus will decide not to support the "different" candidate themselves. This is an important finding. Bateson also considers how to mitigate such strategic discrimination and argues that "for candidates to overcome strategic discrimination, it is most productive to make the case that fielding diverse candidates advances the goal of winning elections."

Bateson's article is noteworthy for its use of an intersectional approach, especially in prompting subjects to think about the diverse candidates in the presidential primaries of 2020. On another, more normative level, this article raises difficult questions about responsibility that might speak to some of the concerns of a larger public who are trying very hard in 2020 to grapple with systemic racism. Here is one of the challenges this research directs us to consider: is it possible for people to avoid taking responsibility for their own hesitations to vote for white women or people of color? Even if people are willing to accept responsibility for their own beliefs, strategic discrimination allows them to avoid responsibility for racist or sexist views by attributing such views to others. Thus, Bateson has uncovered another layer of the systemic nature of discrimination. Many possible questions about crises of democratic legitimacy arise from this finding.

Neill A. O'Brian's article, "Before Reagan: The Development of Abortion's Partisan Divide," notes that public opinion preceded elite thinking in the placing of the abortion issue within a conservative framing. He uses public opinion data to show that voters' attitudes towards abortion had already aligned to move pro-life voters to the Republican party as part of Nixon's Southern strategy, opposing all forms of "rights" as suspect. But he recounts that initially "pro-choice" and "pro-life" positions did not align with left-right or Democratic-Republican framings. O'Brian's essay thus demonstrates another point as well: to assume that abortion is a "women's issue" is to accept a framing of the issue that privileges the view of feminist claims about the meaning of the abortion issue. This point is important to recall, because not all women are committed to greater political power for women; women have been prominent actors in movements against extending the franchise to women, such as the Equal Rights Amendment.

Furthermore, as Jane Junn and Natalie Masuoka demonstrate in their reflection, "The Gender Gap Is a Race Gap: Women Voters in US Presidential Elections," a majority of white women have supported Republican presidential candidates since 1968 (with the exception of 1996; refer to figure 1). This finding undoes the simplistic account of "the gender gap." It also leads us to think about future research that would explore these differences among women, as well as between women and men. Junn and Masuoka warn us about the limits of studying women as opposed to men: "One of the reasons why political scientists have failed to see the distinct variation in partisan choice by race in female voting behavior is the established method of analyzing women in comparison to men." Junn and Masuoka provide a clear and compelling case for using an intersectional analysis to understand voting behavior. Going forward, both in data collection and analysis, it will be important to foster intersectional analyses that raise more complex questions. "Bringing the men back in," thinking more systematically about accountability and responsibility, and using methods that are intersectional are important directions to consider. ${ }^{3}$

\section{Other Content in This Issue}

In addition to the special section, we have three additional articles in this issue. The first is "The Promise of Precommitment in Democracy and Human Rights: The Hopeful, Forgotten Failure of the Larreta Doctrine." In this contribution Tom Long and Max Paul Friedman conducted research across several countries to examine an early and unsuccessful attempt to regionally safeguard democracy and human rights in the Americas. They revisit the efforts of the Uruguayan Foreign Minister to create a multilateral enforcement mechanism to guarantee both in the immediate postwar period. The effort failed because the states of the Western Hemisphere were divided over a persistent dilemma in the study of international relations: How much sovereignty should one cede in order to safeguard international humanitarian standards. 
In "Public Goods and Social Justice," Margaret Kohn considers on what basis the state ought to provide public goods. Rejecting what the market failures, democratic, and normative approaches, Kohn defends instead a position she calls "solidarism," which stresses that political modernity is built on forms of increased interdependence that create unequal benefits and burdens for individuals. Kohn uses this framework to defend state funding of public parks as a means to ameliorate the social injustice resulting from urbanization and industrialization.

In "The Geography of Citizenship Practice: How the Poor Engage the State in Rural and Urban India," Adam Auerbach and Gabrielle Kruks-Wisner examine the expectations that the poor in Northern India have vis-à-vis the state and how these expectations affect their behavior. Comparing inner city and rural districts, they find that urban inhabitants are more skeptical that the state will respond to their needs compared to rural citizens. Urban residents also are attuned to the presence of political brokers who can provide a channel to make claims on the state. In their sample they see distinct patterns where the village poor are much more likely to get direct relief from the state, whereas in the cities political parties play a much bigger role in intervening on behalf of the poor.

\section{A Final Note}

Some of you may have noted that Joan Tronto coauthored this introduction with us. As a new practice, we will invite members of our Editorial Board to do so, particularly when we think they will have unique perspectives and expertise on the topic we highlight in a particular issue. Look for more of these collaborations in the future.

\section{Notes}

1 As the old saw (attributed variously to Bella Abzug and Ewald Nyquist, among others) puts it, "Equality is not when a female Einstein gets promoted to assistant professor: Equality is when a female schlemiel moves ahead as fast as a male schlemiel" (https://www. searchquotes.com/search/\$search_link/\#ixzz6S xIXCNcc).

2 As a matter of full disclosure, both Michael Bernhard and Joan Tronto are cases in the data set.

3 Stolovitch, Wong, and Proctor 2017 have opened up additional layers of systemic discrimination in arguing that scholars need also to "take into account the roles of misogyny and anti-feminism and the ways in which gendered inequalities have long been naturalized and feminist attempt to address them opposed, mocked, and vilified."

\section{References}

Reskin, Barbara E. 1988. "Bringing the Men Back In: Sex Differentiation and the Devaluation of Women's Work." Gender \& Society 2(1): 58-81.

Sandberg, Sheryl, and Nell Scovell. 2013. Lean In: Women, Work, and the Will to Lead. New York: Alfred A. Knopf.

Strolovitch, Dara Z., Janelle S. Wong, and Andrew Proctor. 2017. "A Possessive Investment in White Heteropatriarchy? The 2016 Election and the Politics of Race, Gender, and Sexuality." Politics, Groups, and Identities 5(2): 353-63. 


\section{Statement of Mission and Procedures}

Perspectives on Politics seeks to provide a space for broad and synthetic discussion within the political science profession and between the profession and the broader scholarly and reading publics. Such discussion necessarily draws on and contributes to the scholarship published in the more specialized journals that dominate our discipline. At the same time, Perspectives seeks to promote a complementary form of broad public discussion and synergistic understanding within the profession that isessential toadvancing scholarship and promoting academic community.

Perspectives seeks to nurture a political science public sphere, publicizing important scholarly topics, ideas, and innovations, linking scholarly authors and readers, and promoting broad reflexive discussion among political scientists about the work that we do and why this work matters.

Perspectives publishes work in a number of formats that mirror the ways that political scientists actually write:

Research articles: As a top-tier journal of political science, Perspectives accepts scholarly research article submissions and publishes the very best submissions that make it through our double-blind system of peer review and revision. The only thing that differentiates Perspectives research articles from other peer-reviewed articles at top journals is that we focus our attention only on work that in some way bridges subfield and methodological divides, and tries to address a broad readership of political scientists about matters of consequence. This typically means that the excellent articles we publish have been extensively revised in sustained dialogue with the editors to address not simply questions of scholarship but questions of intellectual breadth and readability.

"Reflections" are more reflexive, provocative, or programmatic essays that address important political science questions in interesting ways but are not necessarily as systematic and focused as research articles. These essays often originate as research article submissions, though sometimes they derive from proposals developed in consultation with the editor in chief. Unlike research articles, these essays are not evaluated according to a strict, doubleblind peer review process. But they are typically vetted informally with editorial board members or other colleagues, and they are always subjected to critical assessment and careful line-editing by the editor and editorial staff.

Scholarly symposia, critical book dialogues, book review essays, and conventional book reviews are developed and commissioned by the Associate and Book Review Editor, based on authorial queries and ideas, editorial board suggestions, and staff conversations.

Everything published in Perspectives is carefully vetted and edited. Given our distinctive mission, we work hard to use our range of formats to organize interesting conversations about important issues and events, and to call attention to certain broad themes beyond our profession's normal subfield categories.

For further details on writing formats and submission guidelines, see our website at http://www.apsanet.org/ perspectives/ 